\title{
Associations of mood symptoms with NYHA functional classes in angina pectoris patients: a cross-sectional study
}

\author{
Han Yin ${ }^{1,2}$, Yuting Liu ${ }^{1,2}$, Huan Ma', Guihao Liu', Lan Guo ${ }^{1,3}$ and Qingshan Geng ${ }^{1,2^{*}}$
}

\begin{abstract}
Background: Depression and anxiety are prevalent and associated with a worse prognosis in coronary heart disease (CHD) patients. However, the influence of disease severity on mood symptoms is unknown. The specific associations of mood symptoms with NYHA classes remain unexplored.

Methods: In this cross-sectional study, 443 consecutive inpatients with angina pectoris (AP) confirmed by angiography were included into analysis. Somatic and cognitive symptom scores derived from Patient Health Questionnaire (PHQ-9) and Generalized Anxiety Disorder Scale (GAD-7) were used to assess mood symptoms. Predictors for depression and anxiety with strict and lax standards were compared. We hypothesized NYHA classification to be an indicator of disease severity through analyses with clinical features using ordinal logistic model. Applying both binary and ordinal logistic models, we evaluated the associations of mood symptoms with NYHA classes.
\end{abstract}

Results: Discrepancy of disease severity existed between the depressed and nondepressed. NYHA classification was proved to be an integrated index under influence of age, coronary stenosis, heart failure and diabetes. NYHA class I and II individuals with AP were at equivalent risk for depression (NYHA II vs I: binary model OR $1.32(0.59,2.96), p=0$. 50; ordinal model OR $1.17(0.73,1.88), p=0.52)$, however NYHA class III/IV patients shared a sharply higher risk (NYHA III/IV vs I: binary model OR $3.32(1.28,8.61), p=.013$; ordinal model OR $3.94(2.11,7.36), p<.001)$. Analyses on somatic and cognitive depressive symptoms confirmed this finding and hinted a greater impact of education background on mood when patient's condition is unstable. Anxiety seemed in the whole picture irrelevant with NYHA classes. Comparing with NYHA class I/II, AP patients in NYHA class III/IV tended to be less anxious. However, when CHD became unstable, the calmness may immediately be broken up. A great distinction of the ratio of anxiety and depression symptom scores between NYHA class III/IV stable and unstable AP patients $(p=.018)$ was observed.

Conclusions: Mood symptoms in CHD patients are to a great extend derived from disease itself. Only for patients with relatively serious physical condition, unexpected discomforts caused by disease notably impact the emotions. Education background tends to influence the mood especially when disease is still unstable.

Keywords: Depression, Anxiety, Angina pectoris, New York heart association class

\footnotetext{
* Correspondence: gengqsh@163.net

'Department of Cardiology, Guangdong Cardiovascular Institute, Guangdong

Provincial People's Hospital, Guangdong Academy of Medical Sciences,

No.106 Zhongshan Er Road, Guangzhou 510080, People's Republic of China

${ }^{2}$ School of Medicine, South China University of Technology, Guangzhou,

China

Full list of author information is available at the end of the article
}

(c) The Author(s). 2019 Open Access This article is distributed under the terms of the Creative Commons Attribution 4.0 International License (http://creativecommons.org/licenses/by/4.0/), which permits unrestricted use, distribution, and reproduction in any medium, provided you give appropriate credit to the original author(s) and the source, provide a link to the Creative Commons license, and indicate if changes were made. The Creative Commons Public Domain Dedication waiver (http://creativecommons.org/publicdomain/zero/1.0/) applies to the data made available in this article, unless otherwise stated. 


\section{Background}

Depression and anxiety, more prevalent in CHD patients than the general population, are associated with an increased risk of worse prognosis [1-4]. However, these associations in many studies weaken or vanish when adjusted for variables that can reflect physical conditions [5-7], indicating a close correlation between emotional symptoms and disease severity [8-10]. Few researchers have particularly studied the alteration pattern of mood symptoms along with deterioration of CHD. Reasons for this phenomenon lie: (1) no explicit criteria exists for disease severity grading; (2) it seems a common sense for seriously ill patients to be in a bad state of mind. It is obvious that disease severity influences the clinical outcomes. Knowing the specific association of mood symptoms with disease severity may help to reach a better understanding of the impact of mood on prognosis, see through some confusing findings about anxiety and depression and find out the most efficient therapies for patients.

Searching through the articles, there are hardly any researches adjusting with same variables to eliminate the influence of disease severity on outcomes. New York Heart Association (NYHA) classification [11], as a widely used clinical tool which emphasizes the subjective cardiac symptoms on daily activity, possesses good predictive value of cardiopulmonary function [12, 13], physical status [14], quality of life [15] and clinical outcomes for example stroke [16], hospitalization [15] and mortality $[15,17]$. We hypothesize NYHA class to be a simple but integrated indicator of physical status and can be utilized to assess the associations of mood symptoms with physical condition.

To fully understand the differences of emotional state under different physical condition, and under the background that several recent studies report that somatic rather than cognitive depressive symptoms correlate with lower heart rate variability [18] and predict worse long-term outcomes in CHD patients [19-22]. we split PHQ-9 into somatic and cognitive depressive symptoms based on confirmatory factor analysis and analyzed the correlation of depression, anxiety and their internal relations with NYHA classes in both stable angina pectoris (SAP) and unstable angina pectoris (UAP) patients. Through all these analyses, we hoped to reach a better understanding of mood symptoms in CHD patients and its change pattern along with worsening of physical condition. This may be of guiding significance for the timing of intervention and the selection of treatment.

\section{Methods}

Design

This is a cross-sectional study for investigating the discrepancies of mood symptoms of Chinese patients in different coronary condition and CHD subtypes and the determinants for depression and anxiety. 705 consecutive inpatients with primary diagnosis of CHD at admission in Guangdong Provincial People's Hospital were surveyed between October 2017 and January 2018. Results of clinical tests and coronary angiography (CAG) as well as discharge diagnosis were acquired from medical records to ensure the correct patient categorization (Fig. 1). Chinese version of PHQ-9, GAD-7 and a self-designed short questionnaire about valuable information were applied. All participants were surveyed in comparatively stable condition and under supervision of one well-trained psycho-cardiologist, who was responsible for elucidating the PHQ-9 and GAD-7 questionnaires, assisting patients with failing eyesight or low literacy and conducting a concise review to guarantee data accuracy.

\section{Patients selection}

The current paper concerns a cross-sectional analysis of the baseline status of the angina pectoris inpatients. Inpatients with main discharge diagnosis of angina pectoris and a history of coronary artery bypass grafting or coronary stent implantation or with at least one narrow epicardial coronary artery $(\geq 50 \%)$ confirmed by CAG during this hospitalization were included. Participants with severe valvular heart disease, or severe cardiomyopathy unlikely caused by coronary stenosis, or other complications that might interfere the mechanism that symptoms were primarily resulted from the narrowed coronary were excluded, leaving a sample of 443 subjects (187 SAP and 256 UAP according to Braunwald criteria [23]) into analysis (Fig. 1). The study was approved by the Medical Ethics Committee of Guangdong Provincial People's Hospital. Written informed consent were obtained from all participants.

\section{New York heart association classification}

NYHA classification [11] is a widely used clinical tool that measures the cardiac functional capacity. The assessment of NYHA class was mainly based on the medical records at admission. However, for the missing data, two cardiologists separately estimated the NYHA class and discussed with a third doctor if inconsistence appeared. To unify the criteria, we defined that conditions triggering fatigue, palpitation, dyspnea, or anginal pain of NYHA class III patients were walking $20-100 \mathrm{~m}$ or climbing one flight of stairs at normal pace.

\section{Patient health questionnaire - 9}

The PHQ-9 is a valid screening tool for depression in accordance with DSM-IV criteria for major depressive disorder (MDD) [24, 25]. The 9 items which evaluate the depression symptoms are rated on a $0-3$ Likert-type 


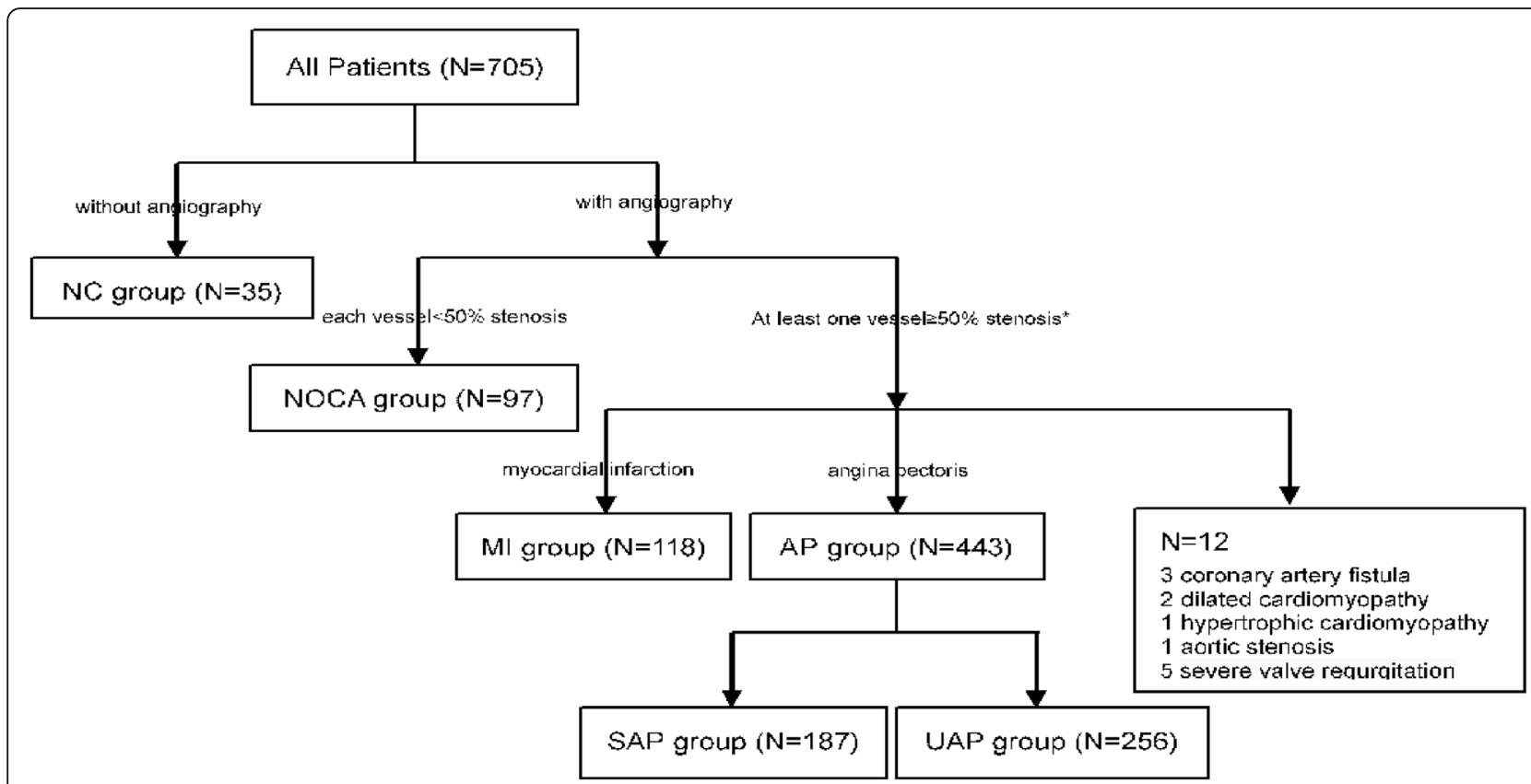

Fig. 1 Categorization of inpatients surveyed in study. Abbreviation: NC: no coronary angiography; NOCA: no obstructive coronary artery; MI: myocardial infarction; AP: angina pectoris; SAP: stable angina pectoris; UAP: unstable angina pectoris. *: inpatients with at least one obstructive vessel $(\geq 50 \%)$ confirmed by coronary angiography or with a history of coronary artery bypass grafting or coronary stent implantation were included

scale with higher score on each item representing more frequently being bothered by the symptom in the last 2 weeks. It has been demonstrated to be a reliable predictor of depression severity with mild, moderate, moderately severe to severe depression corresponding to a score of 5, 10 and 15, respectively [24]. PHQ-9 score $\geq$ 10 indicates clinical depression and has a sensitivity of $88 \%$ and a specificity of $88 \%$ for major depression [25]. Given the fact that even mild depression symptom classified by PHQ-9 is associated with a worse prognosis of cardiac patients [26], clinical characteristics between subjects with PHQ-9 score $<5$ and $\geq 5$ have also been compared. The Chinese version of PHQ-9 has been validated in Chinese cardiac patients [27].

\section{Somatic and cognitive depressive symptoms}

A number of researches have proved that PHQ-9 has two-factor structure and can be divided into somatic and cognitive depression symptom subscales. To be accurate, we listed 5 representative models (one-factor model: Model 1 [28]; four two-factor models: Model 2a [29-31], Model 2b [18, 19, 21], Model 2c [32-34], Model 2d [30]) (see Additional file 1: Table S1), and implemented confirmatory factor analysis (CFA) with items as continuously-scaled and maximum likelihood estimation with a mean-adjustment analysis method for non-normality data using Mplus 7 software. Model 2c turned out to be the best model with fit indices indicating adequately fit [35]. Internal consistency coefficients (Cronbach's $\alpha$ ) were 0.76 for factor 1 (somatic) and 0.79 for factor 2 (cognitive). The error-free factors were correlated at 0.85 . We accordingly calculated the sum scores of the two dimensions as factor scores (somatic and cognitive).

\section{Generalized anxiety disorder scale- 7}

GAD-7 is a 7-item self-report scale based on DSM-IV criteria [36]. Items of GAD-7 are also rated on a $0-3$ Likert-type scale. It measures the severity of generalized anxiety disorders and also exhibits good convergent validity when compared with other commonly-used anxiety scales [37]. Total score ranges from 0 to 21 with a score of 0-4, 5-9, 10-14, 15-21 representing normal, mild, moderate and severe levels of anxiety, respectively. Analogously, GAD-7 score $\geq 10$ indicates clinical anxiety, since the sensitivity and specificity for generalized anxiety disorder reached 89 and $82 \%$, respectively. The minimal clinical important difference has not been established. Considering the widely use of the cutoff of 5 to distinguish patients from normal state, differences between patients with GAD-7 score $<5$ and $\geq 5$ have also been compared. The Chinese version of GAD-7 has been validated in Chinese cardiac patients [38]. Previous studies have shown the underlying structure of GAD-7 to be unidimension [37, 39]. 
Coronary artery stenosis severity, education background and creatinine clearance

Coronary artery stenosis severity was assessed according to the number of three main vessels with stenosis $\geq 50 \%$ as shown by angiography. However, $a \geq 30 \%$ lumen stenosis in left main coronary artery would be directly classified as the highest level of severity.

Due to the difference of education systems, the schooling year for participants in each stage may not be the same. The four levels of education background represented illiteracy or primary school, junior high school, senior high school and technical school or college or university level.

Creatinine clearance was estimated using the Cockcroft-Gault formula with the value of serum creatinine tested at admission.

\section{Statistical analysis}

Statistical analysis mainly contained three parts: (1) We first compared patients' characteristics according to different cutoffs for depression and anxiety to figure out the dominant predictors of mood disturbance; (2) Next, we evaluated whether NYHA classification could be an integrated index indicating patients' status; (3) Finally, we explored the association between NYHA classes and depression or anxiety symptoms.

-Part 1 Clinical characteristics were compared between patients with questionnaire score $<10$ and $\geq 10$ as well as $<5$ and $\geq 5$ with Student's t-test and Wilcoxon rank-sum test for continuous variables and Chi-square or Fisher's Exact test or Cochran-Mantel-Haenszel test for categorical variables.

-Part 2 Since only 6 patients were categorized as NYHA IV, we incorporated NYHA III and NYHA IV and compared clinical characteristics between the 3 groups using one-way analysis of variance (ANOVA) or chi-square tests or Kruskal-Wallis test. We chose to model NYHA classes (I, II, III/IV) as ordinal outcomes using ordinal logistic regression, adjusting for all physical condition variables with a significant association in univariate analyses along with age, sex, body mass index and education background.

-Part 3 We conducted ordinal logistic regression analyses taking into account all depression and anxiety severities as ordinal outcomes $(0,1,2,3)$ and compared the results with binary logistic regression models, which treated questionnaire scores as dichotomous outcome variables with the cutoff point of 10. Analogous analyses were also made with somatic and cognitive depressive symptom scores through converting them to dichotomous variables depending on whether the upper quartile was reached. All models were adjusted for age, sex, body mass index (BMI) and education background. The correlation between PHQ-9 and GAD-7 scores was assessed using Pearson's correlation coefficients. Their internal relation of AP, SAP and UAP patients in different NYHA classes were analyzed with linear regression model and plotted with $\mathrm{R}$ software (version 3.5.1). Ratio of anxiety and depression symptom score between SAP and UAP groups was compared using Student's t-test.

Except for data of Nt-ProBNP and LVEF, model independent variates were missing for at least 1 study variate in 14 patients $(3.2 \%)$, with no study variate having > $1.8 \%$ missing data. Mean or median imputation depending on distribution pattern were applied using SAS STDIZE procedure. All tests for significance were two-tailed at the threshold of 0.05 and were performed with SAS 9.4 software.

\section{Results}

Predictors of elevated depression and anxiety symptoms Of the 443 consecutive angina pectoris inpatients screened, 123(27.8\%), 34(7.7\%) and 15(3.4\%) inpatients were categorized as with mild, moderate and moderately severe to severe depression symptom, 103(23.3\%), $13(2.9 \%), 11(2.5 \%)$ with mild, moderate and severe anxiety symptom. Patients' characteristics were presented in Table 1 and Additional file 2: Table S2.

Compared with individual who had no or mild depression symptom, those with clinical depression (PHQ-9 score $\geq 10$ ) were more likely to be less educated ( $p$ $=.041)$, with higher NYHA classes $(p=.017)$ and a history of antidepressant treatment $(p<.001)$. A slight trend toward significance was observed for a prescription of loop diuretics $(p=.062)$ or aldosterone receptor antagonist $(p=.083)$. However, when comparing those not depressed with depressed patients, features that marked worse physical status became quite outstanding (see Table 1). Besides, the depressed participants tended to be older $(p=.019)$, female $(p<.001)$, without marriage partner $(p=.023)$ and less educated $(p<.001)$. The average scores of somatic depressive depression symptoms in each depression severity groups were 1.39 (SD 1.18), 4.37 (SD 1.44), 8.90 (SD 2.81), taking up 78.1, 68.9 and $63.3 \%$ of the total score, respectively.

Unlike depression, no difference except for an antidepressant treatment history $(p=.010)$ was observed between the patients with or without clinical anxiety. Interestingly in comparison of the anxious and non-anxious, we noticed that anxious subjects tended to be female $(p<.001)$, less educated $(p=.001)$, with less severe coronary artery stenosis $(p=.050)$ and a history of antidepressant treatment $(p<.001)$ (see Additional file 2: Table S2).

\section{NYHA classes and clinical characteristics}

In univariate analyses (Table 2), we discovered that significant differences existed among groups in age $(p$ 
Table 1 Characteristics of patients stratified by depression severity

\begin{tabular}{|c|c|c|c|c|c|c|}
\hline \multirow[t]{4}{*}{ Variables } & \multirow[t]{2}{*}{ Total } & \multirow[t]{2}{*}{ Non-depressed } & \multicolumn{2}{|l|}{ depressed } & \multirow[t]{2}{*}{$p$ value } & \multirow[t]{2}{*}{$p$ value } \\
\hline & & & mild dep. & mod-severe dep. & & \\
\hline & \multirow[t]{2}{*}{$N=443$} & $N=271$ & $N=123$ & $N=49$ & \multirow{2}{*}{$\begin{array}{l}\text { not } \\
\text { clinical } \\
\text { vs } \\
\text { clinical }\end{array}$} & \multirow{2}{*}{$\begin{array}{l}\text { nondepressed } \\
\text { vs depressed }\end{array}$} \\
\hline & & $61.2 \%($ score $<5)$ & $27.8 \%$ & $11.1 \%($ score $\geq 10)$ & & \\
\hline \multicolumn{7}{|l|}{ Demographics } \\
\hline Age,mean $\pm S D, y$ & $63.9 \pm 9.8$ & $63.0 \pm 9.5$ & $65.5 \pm 10.0$ & $64.9 \pm 10.8$ & 0.47 & .019 \\
\hline Male,No.(\%) & $337(76.1)$ & $223(82.3)$ & $79(64.2)$ & $35(71.4)$ & 0.42 & $<.001$ \\
\hline Body mass index,mean $\pm \mathrm{SD}, \mathrm{kg} / \mathrm{m} 2$ & $24.5 \pm 3.1$ & $24.6 \pm 2.7$ & $24.4 \pm 3.5$ & $24.2 \pm 3.7$ & 0.51 & 0.41 \\
\hline \multicolumn{7}{|l|}{ Clinical characteristics } \\
\hline NYHA class I-IV,No.(\%) & & & & & .017 & $<.001$ \\
\hline Class I & 115(26.0) & $79(29.2)$ & $27(22.0)$ & $9(18.4)$ & & \\
\hline Class II & 261(58.9) & 169(62.4) & $66(53.7)$ & $26(53.1)$ & & \\
\hline Class III-IV & $67(15.1)$ & $23(8.5)$ & $30(24.4)$ & 14(28.6) & & \\
\hline Ejection Fraction,mean \pm SD, $\%$ & $59.3 \pm 11.0$ & $60.3 \pm 9.9 N=238$ & $56.4 \pm 12.3 N=112$ & $60.8 \pm 12.0 N=43$ & 0.33 & .024 \\
\hline Nt-ProBNP,median(interquartile),pg/mL & $123(50-382)$ & $106(48-309) N=231$ & $180(72-721) N=99$ & $124(47-341) N=39$ & 0.98 & .013 \\
\hline Creatinine Clearance,mean \pm SD,ml/min & $65.5 \pm 21.7$ & $68.4 \pm 20.1$ & $61.1 \pm 22.4$ & $60.7 \pm 26.3$ & 0.17 & $<.001$ \\
\hline Type of angina pectoris,No.(\%) & & & & & 0.92 & 0.94 \\
\hline Unstable angina pectoris & $256(57.8)$ & 157(57.9) & $71(57.7)$ & $28(57.1)$ & & \\
\hline Stable angina pectoris & 187(42.2) & 114(42.1) & $52(42.3)$ & $21(42.9)$ & & \\
\hline Severity of coronary stenosis,No.(\%) & & & & & 0.62 & 0.34 \\
\hline 1 & $93(21.0)$ & $51(18.8)$ & $33(26.8)$ & $9(18.4)$ & & \\
\hline 2 & $82(18.5)$ & 54(19.9) & 19(15.4) & $9(18.4)$ & & \\
\hline 3 & $268(60.5)$ & 166(61.3) & $71(57.7)$ & $31(63.3)$ & & \\
\hline \multicolumn{7}{|l|}{ Social factors } \\
\hline Education,No.(\%) & & & & & .041 & $<.001$ \\
\hline less than 6 years & 115(26.0) & $50(18.5)$ & $44(35.8)$ & $21(42.9)$ & & \\
\hline 7-9years & $126(28.4)$ & $85(31.4)$ & $31(25.2)$ & $10(20.4)$ & & \\
\hline 10-12 years & $97(21.9)$ & $63(23.2)$ & $25(20.3)$ & $9(18.4)$ & & \\
\hline more than 12 years & $105(23.7)$ & $73(26.9)$ & 23(18.7) & $9(18.4)$ & & \\
\hline Marriage,No.(\%) & & & & & .068 & .023 \\
\hline Married & $412(93.0)$ & 258(95.2) & 112(91.1) & $42(85.7)$ & & \\
\hline Divorced or Widowed or Single & $31(7.0)$ & $13(4.8)$ & $11(8.9)$ & $7(14.3)$ & & \\
\hline \multicolumn{7}{|l|}{ Medical history,No.(\%) } \\
\hline Hypertension & $276(62.3)$ & $162(59.8)$ & $78(63.4)$ & $34(69.4)$ & 0.25 & 0.26 \\
\hline Diabetes mellitus & 154(34.8) & 83(30.6) & $52(42.3)$ & 19(38.8) & 0.53 & .022 \\
\hline Prior $\mathrm{PCl}$ & 167(37.7) & 102(37.6) & $43(35.0)$ & $22(44.9)$ & 0.27 & 0.97 \\
\hline History of antidepressant treatment & $17(3.8)$ & $4(1.5)$ & $6(4.9)$ & $7(14.3)$ & $<.001$ & .001 \\
\hline \multicolumn{7}{|l|}{ Medication use,No.(\%) } \\
\hline ACEI or ARB & $317(71.6)$ & 190(70.1) & $93(75.6)$ & $34(69.4)$ & 0.72 & 0.40 \\
\hline$\beta$ blocker & $384(86.7)$ & $230(84.9)$ & 109(88.6) & 45(91.8) & 0.26 & 0.16 \\
\hline Mono antipletelet therapy & $63(14.2)$ & $38(14.0)$ & 19(15.4) & $6(12.2)$ & 0.67 & 0.88 \\
\hline Dual antiplatelet therapy & $370(83.5)$ & $228(84.1)$ & 100(81.3) & $42(85.7)$ & 0.66 & 0.66 \\
\hline Statin & 430(97.1) & 266(98.2) & 120(97.6) & $47(95.9)$ & 0.36 & 0.46 \\
\hline Aldosterone receptor antagonist & $42(9.5)$ & $16(5.9)$ & $18(14.6)$ & $8(16.3)$ & .083 & .001 \\
\hline
\end{tabular}


Table 1 Characteristics of patients stratified by depression severity (Continued)

\begin{tabular}{|c|c|c|c|c|c|c|}
\hline \multirow[t]{4}{*}{ Variables } & \multirow[t]{2}{*}{ Total } & \multirow[t]{2}{*}{ Non-depressed } & \multicolumn{2}{|l|}{ depressed } & \multirow[t]{2}{*}{$p$ value } & \multirow[t]{2}{*}{$p$ value } \\
\hline & & & mild dep. & mod-severe dep. & & \\
\hline & \multirow[t]{2}{*}{$N=443$} & $N=271$ & $N=123$ & $N=49$ & \multirow{2}{*}{$\begin{array}{l}\text { not } \\
\text { clinical } \\
\text { vs } \\
\text { clinical }\end{array}$} & \multirow{2}{*}{$\begin{array}{l}\text { nondepressed } \\
\text { vs depressed }\end{array}$} \\
\hline & & $61.2 \%($ score $<5)$ & $27.8 \%$ & $11.1 \%$ (score $\geq 10)$ & & \\
\hline Loop diuretic & $47(10.6)$ & $18(6.6)$ & $20(16.3)$ & $9(18.4)$ & .062 & $<.001$ \\
\hline Anticoagulant & $20(4.5)$ & $10(3.7)$ & $8(6.5)$ & $2(4.1)$ & $>0.99$ & 0.29 \\
\hline Antidepressant & $9(2.0)$ & $4(1.5)$ & $0(0)$ & $5(10.2)$ & .001 & 0.49 \\
\hline Somatic symptom score,mean(SD) & $3.05(2.87)$ & $1.39(1.18)$ & $4.37(1.44)$ & $8.90(2.81)$ & $<.001$ & $<.001$ \\
\hline Cognitive symptom score,mean(SD) & $1.36(1.98)$ & $0.39(0.63)$ & $1.98(1.46)$ & $5.16(2.73)$ & $<.001$ & $<.001$ \\
\hline Somatic / Dep. symptom score,\% & 69.2 & 78.1 & 68.9 & 63.3 & & \\
\hline
\end{tabular}

Note: Clinical characteristics were compared between subjects with PHQ-9 score $<10$ and $\geq 10$ (not clinical vs clinical) as well as $<5$ and $\geq 5$ (non-depressed vs depressed)

Abbreviation: dep.: depression; mod-severe dep.: moderate or severe depression; PCI: percutaneous transluminal coronary intervention; ACEl: angiotensin converting enzyme inhibitor; ARB: angiotensin receptor blocker

$<.001)$, EF $(p<.001)$, Nt-ProBNP $(\mathrm{p}<.001)$, creatinine clearance $(p<.001)$, coronary artery stenosis severity $(p$ $<.001)$, medical history of hypertension $(p=.003)$ or diabetes $(p<.001)$, prescription of loop diuretics $(p<.001)$ or aldosterone receptor antagonist $(p<.001)$, depression severity $(p<.001)$, somatic $(p<.001)$ and cognitive $(p$ $<.001)$ depressive symptoms, but not in anxiety severity $(p=0.99)$, type of AP $(p=0.24)$, nor education background $(p=0.83)$. After multivariate adjustment using ordinal logistic regression model, significance retained for age $(p=.024)$, $\operatorname{EF}(p=.037)$, Nt-ProBNP $(p=.006)$, coronary artery stenosis severity $(p=.034)$ and history of diabetes $(p=.016)$ (see Additional file 3: Table S3), revealing a multiple impact of age, $\mathrm{CHD}$ severity, diabetes and heart failure on NYHA classes.

\section{Associations of NYHA classes with depression and anxiety} The Pearson's correlation coefficients of PHQ-9 and GAD-7 scores was $0.72(p<.001)$. As shown in Fig. 2 , a non-differential interrelationship of depression and anxiety in different NYHA classes in AP (Fig. 2.A) and UPA patients (Fig. 2.C) was observed. For SAP, subjects in NYHA class III/IV seemed to be less anxious than those in NYHA class I and II under the same level of depression (Fig. 2.B). The ratio of anxiety and depression symptom scores differed significantly between SAP and UAP patients in NYHA class III/IV with at least mild depression symptoms $(p=.018)$, but no difference between groups exited in separate analyses neither for anxiety nor depression.

Comparing the results of the binary and ordinal logistic models (see Table 3), a great consistency was observed in analyses for depression and anxiety in SAP patients, but not in UAP counterparts. For SAP patients, NYHA classes was significantly associated with levels of depression (binary model: $p=.010$; ordinal model: $p$
$<.001)$. This close correlation was also verified in UAP patients though only with ordinal model (binary model: $p=0.46$; ordinal model: $p=.005$ ). Detailed analyses demonstrated that NYHA class I and II subjects in all AP types were statistically at equivalent risk for depression (for AP: NYHA II vs I binary model OR $1.32(0.59,2.96)$, $p=0.50$; ordinal model OR $1.17(0.73,1.88), p=0.52)$, although NYHA II subjects with UAP seemed more likely to be depressed in comparison with those SAP counterparts through the results of both models and analyses of somatic and cognitive depressive symptoms. One possible reason for this phenomenon is that SAP patients in NYHA class II may more frequently have the psychological expectancy of angina when doing excessive activities, but NYHA class I patients may not. NYHA III/IV patients, by contrast, shared a sharply higher risk (for AP: NYHA III/IV vs I binary model OR $3.32(1.28,8.61)$, $p=.013$; ordinal model OR $3.94(2.11,7.36), p<.001)$. NYHA class was found to be not associated with levels of anxiety regardless of the AP types. Additionally, education background was demonstrated to correlate with the risk for depression and anxiety only in UAP inpatients.

Similar trend was also revealed in binary logistic analyses for somatic and cognitive depressive symptoms as shown in Table 4. The only difference beyond their synchronous changes was that cognitive depressive symptoms in UAP and AP patients were affected by gender (for UAP patients: OR $2.11(1.08,4.11), p=.029$; for AP patients: OR $1.82(1.10,3.01), p=.020)$, but somatic symptoms were not.

\section{Discussion}

In a sample of 443 AP inpatients, we compared patients' characteristics according to different cutoffs for depression and anxiety and inferred that depression symptoms 
Table $\mathbf{2}$ Characteristics of patients stratified by New York Heart Association functional class

\begin{tabular}{|c|c|c|c|c|c|}
\hline \multirow[t]{3}{*}{ Variables } & \multirow{3}{*}{$\begin{array}{l}\text { Total } \\
N=443\end{array}$} & NYHA class I & \multirow{2}{*}{$\begin{array}{l}\text { NYHA class II } \\
N=261\end{array}$} & \multirow{2}{*}{$\begin{array}{l}\text { NYHA class III-IV } \\
N=67\end{array}$} & \multirow[t]{3}{*}{$p$ value } \\
\hline & & $N=115$ & & & \\
\hline & & $26.0 \%$ & $58.9 \%$ & $15.1 \%$ & \\
\hline \multicolumn{6}{|l|}{ Characteristic of patients } \\
\hline Age,mean $\pm S D, y$ & $63.9 \pm 9.8$ & $61.3 \pm 9.3$ & $64.0 \pm 9.8$ & $68.2 \pm 9.5$ & $<.001$ \\
\hline Male,sex,No.(\%) & $337(76.1)$ & $85(73.9)$ & 199(76.2) & $53(79.1)$ & 0.73 \\
\hline Body mass index,mean $\pm \mathrm{SD}, \mathrm{kg} / \mathrm{m}^{2}$ & $24.5 \pm 3.1$ & $24.5 \pm$ & $24.5 \pm 3.0$ & $24.6 \pm 3.6$ & 0.94 \\
\hline Ejection Fraction,mean \pm SD, $\%$ & $59.3 \pm 11.0$ & $61.0 \pm 8.2 N=100$ & $60.8 \pm 12.3 N=235$ & $50.1 \pm 16.1 N=58$ & $<.001$ \\
\hline Nt-ProBNP,median(interquartile),pg/mL & 123(50-382) & $88(37-234) N=92$ & $118(50-309) N=228$ & $733(133-3892) N=49$ & $<.001$ \\
\hline Creatinine Clearance,mean $\pm S \mathrm{~S}, \mathrm{ml} / \mathrm{min}$ & $65.5 \pm 21.7$ & $69.5 \pm 18.2$ & $67.0 \pm 22.2$ & $53.0 \pm 21.0$ & $<.001$ \\
\hline Type of angina pectoris,No.(\%) & & & & & 0.24 \\
\hline Unstable angina pectoris & $256(57.8)$ & $65(56.5)$ & $158(60.5)$ & $33(49.3)$ & \\
\hline Stable angina pectoris & $187(42.2)$ & $50(43.5)$ & 103(39.5) & $34(50.7)$ & \\
\hline Severity of coronary artery stenosis,No.(\%) & & & & & $<.001$ \\
\hline 1 & $93(21.0)$ & $40(34.8)$ & $46(17.6)$ & $7(10.4)$ & \\
\hline 2 & $82(18.5)$ & 19(16.5) & $54(20.7)$ & $9(13.4)$ & \\
\hline 3 & $268(60.5)$ & $56(48.7)$ & $161(61.7)$ & $51(76.1)$ & \\
\hline \multicolumn{6}{|l|}{ Mood symptoms } \\
\hline Depression severity,No.(\%) & & & & & $<.001$ \\
\hline Non-depressed & $271(61.2)$ & $79(68.7)$ & $169(64.8)$ & 23(34.3) & \\
\hline Mild depression symptom & $123(27.8)$ & $27(23.5)$ & $66(25.3)$ & $30(44.8)$ & \\
\hline Moderate or severe depression symptom & $49(11.1)$ & $9(7.8)$ & $26(10.0)$ & 14(20.9) & \\
\hline Somatic depressive symptom score,mean(SD) & $3.05(2.87)$ & $2.81(2.64)$ & $2.79(2.76)$ & $4.48(3.28)$ & $<.001$ \\
\hline Cognitive depressive symptom score,mean(SD) & $1.36(1.98)$ & $1.21(1.94)$ & $1.20(1.76)$ & $2.24(2.58)$ & $<.001$ \\
\hline Anxiety severity,No.(\%) & & & & & 0.99 \\
\hline Non-anxious & $316(71.3)$ & $80(69.6)$ & 186(71.3) & $50(74.6)$ & \\
\hline Mild anxiety symptom & 103(23.3) & $30(26.1)$ & $62(23.8)$ & $11(16.4)$ & \\
\hline Moderate or severe anxiety symptom & $24(5.4)$ & $5(4.3)$ & $13(5.0)$ & 6(9.0) & \\
\hline \multicolumn{6}{|l|}{ Social economic factors } \\
\hline Education,No.(\%) & & & & & 0.83 \\
\hline less than 6 years & 115(26.0) & 26(22.6) & $69(26.4)$ & $20(29.9)$ & \\
\hline 7-9years & $126(28.4)$ & $33(28.7)$ & $75(28.7)$ & 18(26.9) & \\
\hline $10-12$ years & $97(21.9)$ & $29(25.2)$ & $52(19.9)$ & $16(23.9)$ & \\
\hline more than 12 years & $105(23.7)$ & $27(23.5)$ & $65(24.9)$ & 13(19.4) & \\
\hline Marriage,No.(\%) & & & & & 0.57 \\
\hline Married & $412(93.0)$ & 109(94.8) & $240(92.0)$ & 63(94.0) & \\
\hline Divorced or Widowed or Single & $31(7.0)$ & $6(5.2)$ & $21(8.0)$ & $4(6.0)$ & \\
\hline \multicolumn{6}{|l|}{ Medical history,No.(\%) } \\
\hline Hypertension & $276(62.3)$ & $56(48.7)$ & $173(44.8)$ & $45(67.2)$ & .003 \\
\hline Diabetes mellitus & 154(34.8) & $28(24.3)$ & $90(34.5)$ & $36(53.7)$ & $<.001$ \\
\hline Prior PCl & $167(37.7)$ & $42(36.5)$ & 93(35.6) & $34(50.7)$ & .069 \\
\hline History of antidepressant treatment & $17(3.8)$ & $4(3.5)$ & $9(3.4)$ & $4(6.0)$ & 0.61 \\
\hline \multicolumn{6}{|l|}{ Medication use,No.(\%) } \\
\hline ACEI or ARB & $317(71.6)$ & $76(66.1)$ & 192(73.6) & $49(73.1)$ & 0.32 \\
\hline$\beta$ blocker & $384(86.7)$ & $95(82.6)$ & 232(88.9) & $57(85.1)$ & 0.23 \\
\hline Aldosterone receptor antagonist & $42(9.5)$ & $2(1.7)$ & $14(5.4)$ & 26(38.8) & $<.001$ \\
\hline Loop diuretic & $47(10.6)$ & $2(1.7)$ & $16(6.1)$ & $29(43.3)$ & $<.001$ \\
\hline Anticoagulant & $20(4.5)$ & $3(2.6)$ & $12(4.6)$ & $5(7.5)$ & 0.31 \\
\hline Antidepressant & $9(2.0)$ & $1(0.9)$ & $6(2.3)$ & 2(3.0) & 0.55 \\
\hline
\end{tabular}

Abbreviation: PCl: percutaneous transluminal coronary intervention; ACEl: angiotensin converting enzyme inhibitor; ARB: angiotensin receptor blocker 


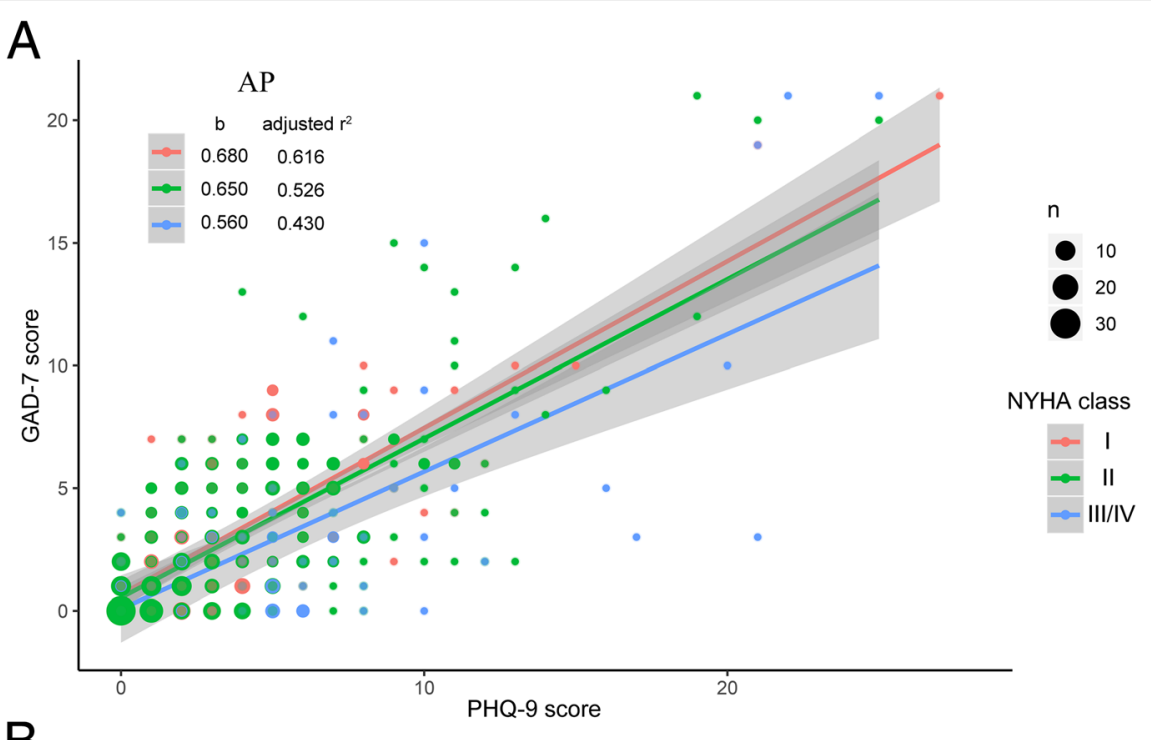

B
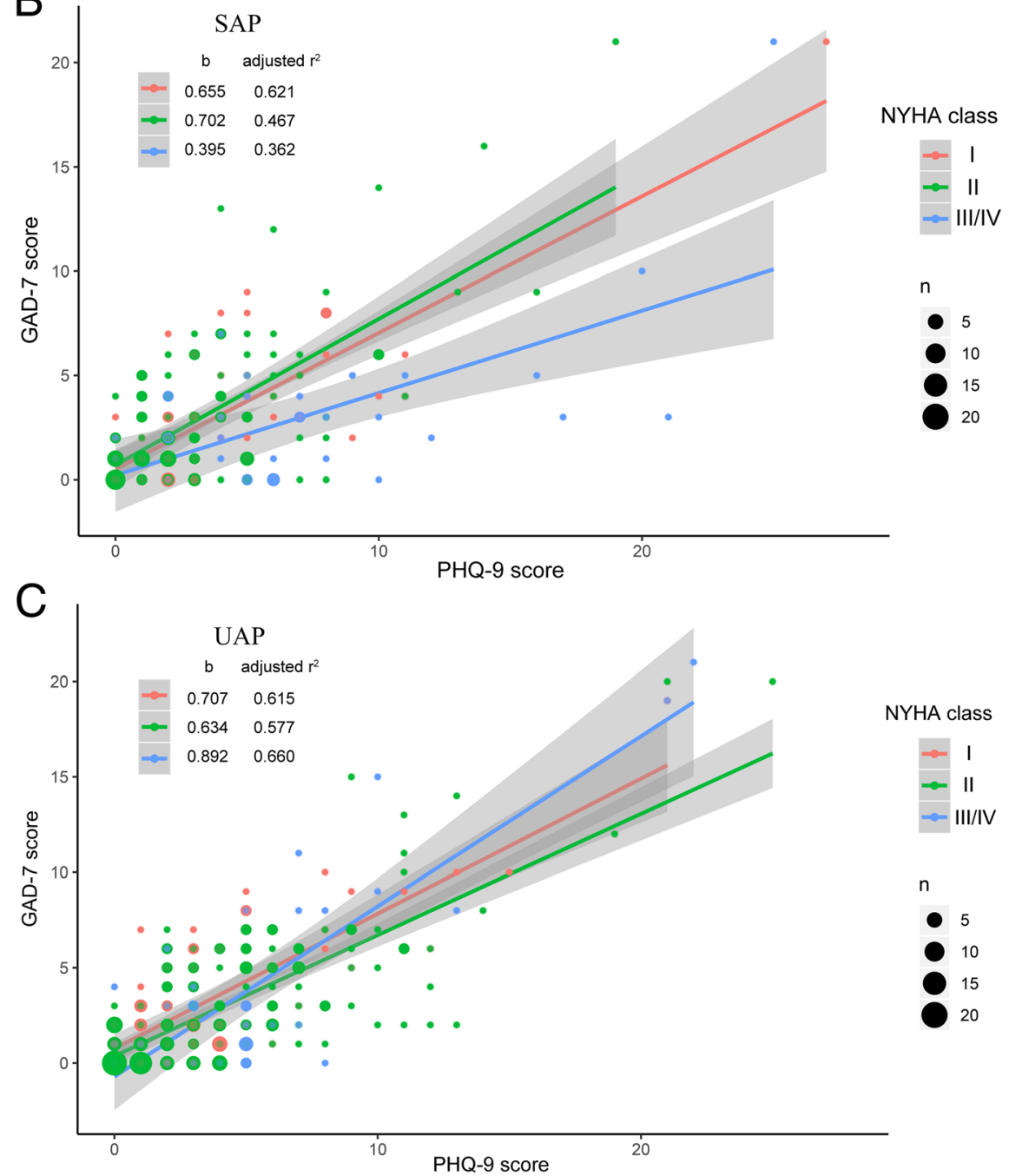

NYHA class

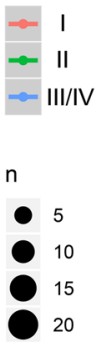

Fig. 2 (See legend on next page.) 
(See figure on previous page.)

Fig. 2 Linear regression analyses of correlations between anxiety and depression symptoms of (a) angina pectoris, (b) stable angina pectoris, and (c) unstable angina pectoris patients in different NYHA classes. Note: The correlations of depression and anxiety in total angina pectoris patients and unstable angina pectoris patients under different NYHA classes were non-differential. However, stable angina pectoris participants in NYHA III/IV seemed to be less anxious under the same level of depression

were aggravated along with the worsening of physical condition. Univariate analyses of NYHA classes with clinical characteristics further confirmed such inference. Next, though multivariate analysis we proved that NYHA classification could be an integrated index reflecting patients' physical status. Finally, we explored the association between NYHA classes and depression or anxiety symptoms and concluded that only for patients with relatively serious physical condition, unexpected discomforts caused by disease notably impacted the emotions.

There has been a debate whether depression disorder in general population is the same thing as in the cardiac patients since long time ago. Our previous analyses of inpatients without or with coronary stenosis $<50 \%$ from the same cross-sectional study sample found the prevalence of clinical depression to be almost twice as high as the one in present study. With the findings mentioned above, it is reasonable to believe that "these two depression disorders" are not the same and may exist at the same time. Analysis of the ratio of somatic and cognitive symptom scores hinted a greater fluctuation of cognitive symptoms with the increase in depression severity. As a result, when cutoff point reached a certain value, the screening for depression becomes more dependent on cognitive symptoms. That is the reason why there is a difference in the results between using the cutoff point of 10 and 5, and why ordinal logistic model is more sensitive to physical condition than binary logistic model.

The rough correlation of mood state and NYHA class has been reported in univariate analyses of considerable previous studies [40-43]. However, in consideration of collinearity with other clinical features such as Pro-BNP, EF, creatinine and so on, few studies have treated NYHA classes as an integrated index reflecting disease severity and explored the associations with mood symptoms in multivariate regression models. Our finding was consistent with the expectation that angina pectoris patients in NYHA class III/IV compared to NYHA class I and II were at greater risk for depression.

In accord with the finding from Assari S. [44], our univariate analyses revealed that for AP patients, less coronary stenosis was associated with elevated anxiety symptoms. It seems that anxiety is more likely to be a stress response. Perhaps our body though constantly adjustment might have learned to "keep calm" in case of sympathetic activation or myocardial ischemia induced by mental stress [45] when with severe CHD. However, when it comes a stress exceeding the threshold physically or mentally, for example the loss of stability of CHD, the calmness may immediately be broken up.

Additionally, quite consistent with our common sense, it was discovered that education background engendered greater effect on mood symptoms in UAP patients. This might attribute to the differences in perception and anticipatory anxiety influenced by knowledge and the social support obtained from social status. In other words, this may indicate that patients in acute phase of CHD for example UAP or even AMI (acute myocardial infarction) can get more benefit from health education, or antidepressant therapy and psychological counseling. Several recent researches have indeed confirmed this hypothesis [46, 47].

To our knowledge, it is the first time that in one study the associations between NYHA classes and depression/ anxiety in both SAP and UAP patients are explored, meanwhile linkage with somatic and cognitive depressive symptoms is assessed. Our findings reveal that depression symptoms in CHD patients are actually to a large extend derived from the disease itself and exacerbate along with the deterioration of physical status especially when $\mathrm{CHD}$ is unstable. Discomfort, as the reason leading to the increment of somatic symptom score, probably at the same time arouses cognitive symptoms. Anxiety symptoms, though generally positively correlate with depression symptoms, may exhibit an inverse relation along with the worsening of physical condition. However, no significant association between NYHA classes and anxiety in the separate analysis was discovered. These findings can at least partly be supported by the phenomenon that left ventricular assist device can help heart failure patients reduce anxiety and depression [48] and antidepressant is hardly to be efficient to improve prognosis in CHD patients $[49,50]$.

Our findings should be considered in light of several potential limitations. First, due to small sample size, NYHA class IV group of patients could not be investigated separately. Therefore, the present study may be unable to represent the seriously ill classification of NYHA IV. Besides, a small sample size might lead to an inaccurate outcome, especially for the analysis on clinical anxious patients and some variables could therefore not been adjusted. However, it should be noted that most of our findings were obtained based on the same outcomes with two criteria, which makes the conclusion more persuasive. Second, this is a single centered study. The advantage is that we could minimize the measuring error by fixing the tester. The disadvantage is that 


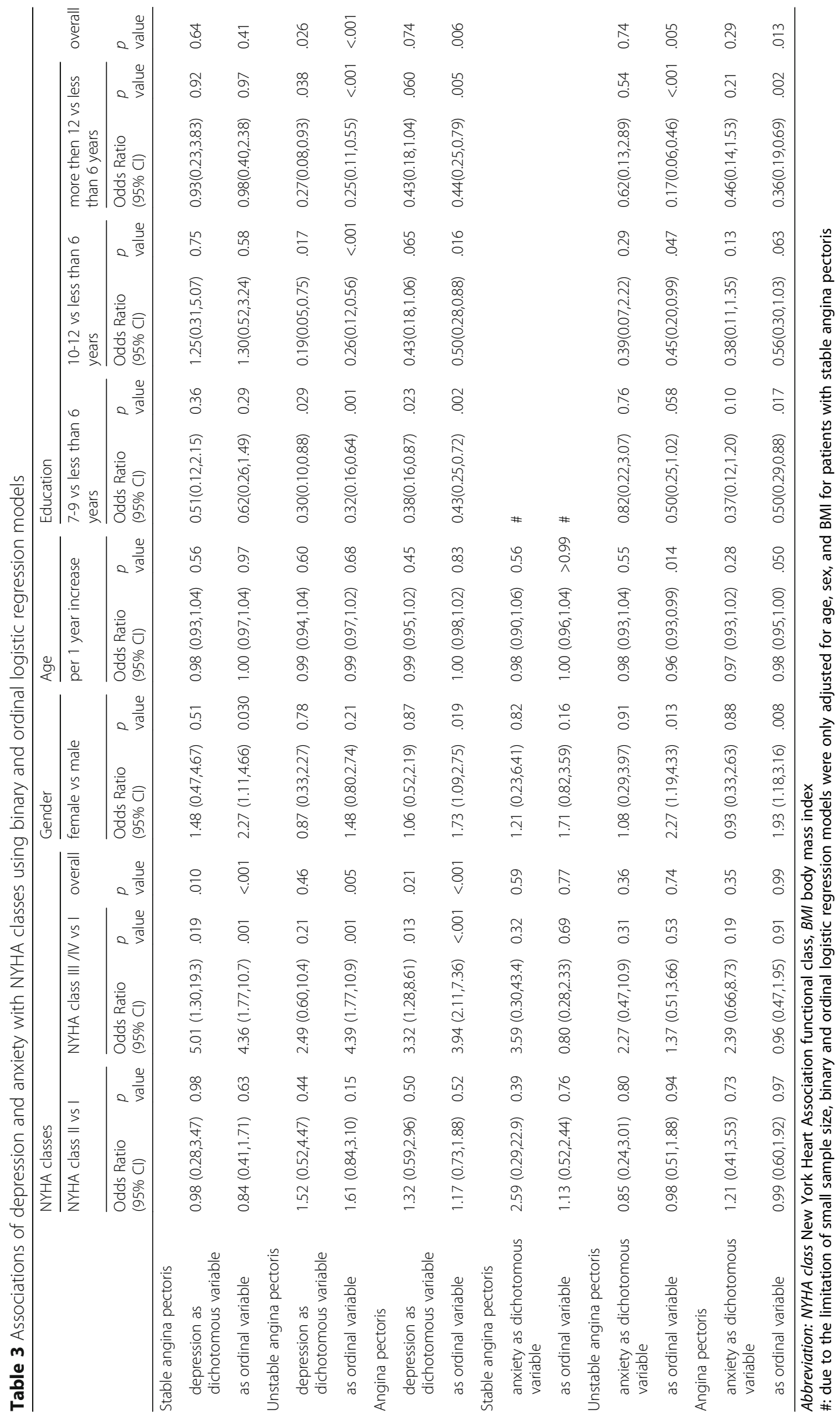




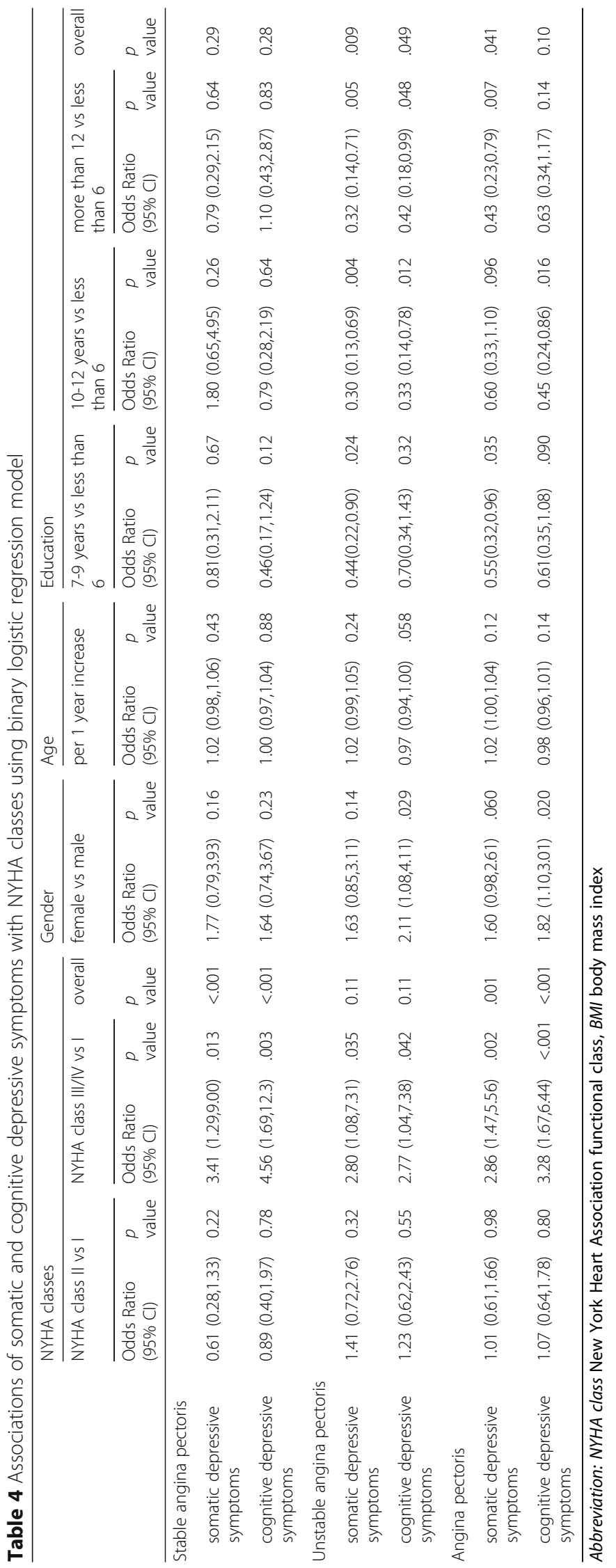


generalizability of the study results needs careful consideration. Third, our data were collected mainly based on the status of patients at admission. Even though all patients were warranted to be surveyed in comparatively stable state, the acute phase of disease was still possible to interfere the assessment results. Lastly, due to the limitation of linear model, we could only from several viewpoints to speculate the complicated interactive relationship between CHD and mood symptoms. More complex model is needed to reveal the deeper associations.

\section{Conclusions}

In summary, our study demonstrated a high synchronized alteration of somatic and cognitive depressive symptoms along with the progress of disease severity. However, more intense mood symptoms are prone to be aroused when patients are in bad functional status. Education background has greater impact on mood when patient's condition is unstable. These findings may trigger deeper rethink of the associations of mood symptoms with $\mathrm{CHD}$ and with the prognosis, lead to a better understanding of the mechanism of mood disorder in CHD patients and help to make the intervention more timely and efficient.

\section{Additional files}

Additional file 1: Table S1. Comparison of fit statistics for the five previously hypothesized factor models of PHQ-9. (DOCX $16 \mathrm{~kb}$ )

Additional file 2: Table S2. Characteristics of patients stratified by anxiety severity. (DOCX $22 \mathrm{~kb}$ )

Additional file 3: Table S3. Association between NYHA classes and clinical features using multivariate ordinal logistic regression model. (DOCX $17 \mathrm{~kb}$ )

\section{Abbreviations}

ACEl: angiotensin converting enzyme inhibitor; AMl: acute myocardial infarction; ANOVA: one-way analysis of variance; AP: angina pectoris; ARB: angiotensin receptor blocker; BMI: body mass index; CAG: coronary angiography; CFA: confirmatory factor analysis; CHD: coronary heart disease; GAD: Generalized Anxiety Disorder Scale; LVEF: left ventricular ejection fraction; NYHA class: New York Heart Association functional class; PCl: percutaneous transluminal coronary intervention; PHQ: Patient Health Questionnaire; SAP: stable angina pectoris; UAP: unstable angina pectoris

\section{Acknowledgments}

We would like to thank Jianfang Luo, MD, Zhujun Chen, MD, Danqing Yu, $M D$, and Ling Wang, MD, the section directors for the support on our research.

\section{Funding}

None.

\section{Availability of data and materials}

The data are accessible upon request.

\section{Authors' contributions}

$\mathrm{YH}$ alone surveyed all patients. LYT, MH collected and entered data into database. LYT, LGH did statistical analyses. YH, GL, GQS wrote the paper.
GQS, GL were senior physicians principally responsible for the study. All authors read and approved the final manuscript.

\section{Ethics approval and consent to participate}

Ethical approval was given by the medical ethics committee of Guangdong General Hospital with the following reference number: No.GDREC2017203H. All participants gave written informed consent.

\section{Consent for publication}

Not applicable.

\section{Competing interests}

The authors declare that they have no competing interests.

\section{Publisher's Note}

Springer Nature remains neutral with regard to jurisdictional claims in published maps and institutional affiliations.

\section{Author details}

${ }^{1}$ Department of Cardiology, Guangdong Cardiovascular Institute, Guangdong Provincial People's Hospital, Guangdong Academy of Medical Sciences, No.106 Zhongshan Er Road, Guangzhou 510080, People's Republic of China. ${ }^{2}$ School of Medicine, South China University of Technology, Guangzhou, China. ${ }^{3}$ Department of Cardiac Rehabilitation, Guangdong Cardiovascular Institute, Guangdong Provincial People's Hospital, Guangdong Academy of Medical Sciences, Guangzhou, China. ${ }^{4}$ Department of Epidemiology, Guangdong Cardiovascular Institute, Guangdong Provincial People's Hospital, Guangdong Academy of Medical Sciences, Guangzhou, China.

Received: 11 November 2018 Accepted: 18 February 2019

Published online: 05 March 2019

References

1. Carney RM, Freedland KE. Depression and coronary heart disease. Nat Rev Cardiol. 2017;14(3):145-55.

2. Roest AM, Martens EJ, de Jonge P, Denollet J. Anxiety and risk of incident coronary heart disease: a meta-analysis. J Am Coll Cardiol. 2010;56(1):38-46.

3. Lichtman JH, Froelicher ES, Blumenthal JA, Carney RM, Doering LV, Frasuresmith N, Freedland KE, Jaffe AS, Leifheitlimson EC, Sheps DS. Depression as a risk factor for poor prognosis among patients with acute coronary syndrome: systematic review and recommendations a scientific statement from the American Heart Association. Circulation. 2014;129(12): 1350-69.

4. Shibeshi WA, Young-Xu Y, Blatt CM. Anxiety worsens prognosis in patients with coronary artery disease. J Am Coll Cardiol. 2007;49(20):2021-7.

5. Meijer A, Conradi HJ, Bos EH, Anselmino M, Carney RM, Denollet J, Doyle F, Freedland KE, Grace SL, Hosseini SH, et al. Adjusted prognostic association of depression following myocardial infarction with mortality and cardiovascular events: individual patient data meta-analysis. The British journal of psychiatry : the journal of mental science. 2013;203(2):90-102.

6. Adelborg K, Schmidt M, Sundboll J, Pedersen L, Videbech P, Botker HE, Egstrup K, Sorensen HT. Mortality risk among heart failure patients with depression: a Nationwide population-based cohort study. J Am Heart Assoc. 2016;5(9).

7. Celano CM, Millstein RA, Bedoya CA, Healy BC, Roest AM, Huffman JC. Association between anxiety and mortality in patients with coronary artery disease: a meta-analysis. Am Heart J. 2015;170(6):1105-15.

8. Lett $\mathrm{H}$, Ali S, Whooley M. Depression and cardiac function in patients with stable coronary heart disease: findings from the heart and soul study. Psychosom Med. 2008;70(4):444-9.

9. Lane D, Ring C, Lip GY, Carroll D. Depression, indirect clinical markers of cardiac disease severity. and mortality following myocardial infarction Heart (British Cardiac Society). 2005;91(4):531-2.

10. Carroll D, Lane D. Depression and mortality following myocardial infarction: the issue of disease severity. Epidemiologia e psichiatria sociale. 2002;11(2):65-8.

11. Bennett JA, Riegel B, Bittner V, Nichols J. Validity and reliability of the NYHA classes for measuring research outcomes in patients with cardiac disease. Heart \& lung : the journal of critical care. 2002;31(4):262-70.

12. Lim FY, Yap J, Gao F, Teo LL, Lam CSP, Yeo KK. Correlation of the New York heart association classification and the cardiopulmonary exercise test: a systematic review. Int J Cardiol. 2018;263:88-93. 
13. Russell SD, Saval MA, Robbins JL, Ellestad MH, Gottlieb SS, Handberg EM, Zhou $Y$, Chandler B. New York heart association functional class predicts exercise parameters in the current era. Am Heart J. 2009;158(4 Suppl):S24-30.

14. Malyszko J, Bachorzewska-Gajewska H, Malyszko J, Levin-laina N, laina A, Dobrzycki S. Prevalence of chronic kidney disease and anemia in patients with coronary artery disease with normal serum creatinine undergoing percutaneous coronary interventions: relation to New York heart association class. The Israel Medical Association journal : IMAJ. 2010;12(8):489-93.

15. Holland R, Rechel B, Stepien K, Harvey I, Brooksby I. Patients' self-assessed functional status in heart failure by New York heart association class: a prognostic predictor of hospitalizations, quality of life and death. J Card Fail. 2010;16(2):150-6.

16. Koren-Morag N, Goldbourt U, Tanne D. Poor functional status based on the New York heart association classification exposes the coronary patient to an elevated risk of ischemic stroke. Am Heart J. 2008;155(3):515-20.

17. Asano R, Kajimoto K, Oka T, Sugiura R, Okada H, Kamishima K, Hirata T, Sato N. Association of new York Heart Association functional class IV symptoms at admission and clinical features with outcomes in patients hospitalized for acute heart failure syndromes. Int J Cardiol. 2017;230:585-91.

18. de Jonge $P$, Mangano D, Whooley MA. Differential association of cognitive and somatic depressive symptoms with heart rate variability in patients with stable coronary heart disease: findings from the heart and soul study. Psychosom Med. 2007;69(8):735-9.

19. Smolderen KG, Spertus JA, Reid KJ, Buchanan DM, Krumholz HM, Denollet J, Vaccarino V, Chan PS. The Association of Cognitive and Somatic Depressive Symptoms with Depression Recognition and outcomes after myocardial infarction. Circulation Cardiovascular Quality \& Outcomes. 2009;2(4):328.

20. de Miranda Azevedo R, Roest AM, Hoen PW, de Jonge P. Cognitive/affective and somatic/affective symptoms of depression in patients with heart disease and their association with cardiovascular prognosis: a meta-analysis. Psychol Med. 2014:44(13):2689-703

21. Hoen PW, Whooley MA, Martens EJ, Na B, van Melle JP, de Jonge P. Differential associations between specific depressive symptoms and cardiovascular prognosis in patients with stable coronary heart disease. J Am Coll Cardiol. 2010;56(11):838-44.

22. Schiffer AA, Pelle AJ, Smith OR, Widdershoven JW, Hendriks EH, Pedersen SS. Somatic versus cognitive symptoms of depression as predictors of all-cause mortality and health status in chronic heart failure. The Journal of clinical psychiatry. 2009;70(12):1667-73.

23. Braunwald E. Unstable angina. A classification. Circulation. 1989;80(2):410-4.

24. Kroenke K, Spitzer RL. The PHQ-9: a new depression and diagnostic severity measure. Psychiatr Ann. 2002;32(9):509-21.

25. Kroenke K, Spitzer RL, Williams JB. The PHQ-9: validity of a brief depression severity measure. J Gen Intern Med. 2001;16(9):606-13.

26. Bhatt KN, Kalogeropoulos AP, Dunbar SB, Butler J, Georgiopoulou W. Depression in heart failure: can PHQ-9 help? Int J Cardiol. 2016;221:246-50.

27. Zhu Y, Blumenthal JA, Shi C, Jiang R, Patel A, Zhang A, Yu X, Gao R. Wu Y: sedentary behavior and the risk of depression in patients with acute coronary syndromes. Am J Cardiol. 2018;121(12):1456-60.

28. Baas KD, Cramer AO, Koeter MW, Eh VDL, van Weert HC, Schene AH. Measurement invariance with respect to ethnicity of the patient health Questionnaire-9 (PHQ-9). J Affect Disord. 2011;129(1-3):229.

29. Krause JS, Bombardier C, Carter RE. Assessment of depressive symptoms during inpatient rehabilitation for spinal cord injury: is there an underlying somatic factor when using the PHQ? Rehabilitation Psychology. 2008;27(53):513-20.

30. Krause JS, Reed KS, Mcardle JJ. Factor structure and predictive validity of somatic and nonsomatic symptoms from the patient health questionnaire9: a longitudinal study after spinal cord injury. Archives of Physical Medicine \& Rehabilitation. 2010;91(8):1218-24

31. Hawkins MA, Dolansky MA, Schaefer JT, Fulcher MJ, Gunstad J, Redle JD, Josephson R, Hughes JW. Cognitive function in heart failure is associated with nonsomatic symptoms of depression but not somatic symptoms. The Journal of cardiovascular nursing. 2015;30(5):E9-e17.

32. Elhai JD, Contractor AA, Tamburrino M, Fine TH, Prescott MR, Shirley E, Chan PK, Slembarski R, Liberzon I, Galea S. The factor structure of major depression symptoms: a test of four competing models using the patient health Questionnaire-9. Psychiatry Res. 2012;199(3):169-73.

33. Petersen JJ, Paulitsch MA, Hartig J, Mergenthal K, Gerlach FM, Gensichen J. Factor structure and measurement invariance of the patient health Questionnaire-9 for female and male primary care patients with major depression in Germany. J Affect Disord. 2015;170:138-42.
34. Richardson EJ, Richards JS. Factor structure of the PHQ-9 screen for depression across time since injury among persons with spinal cord injury. Rehabilitation Psychology. 2008;53(2):243-9.

35. Hu Lt BPM. Cutoff criteria for fit indexes in covariance structure Anaysis: conventional criteria versus new alternatives. Struct Equ Model. 1999;6(1):1-55.

36. Spitzer RL, Kroenke K, Williams JB, Lowe B. A brief measure for assessing generalized anxiety disorder: the GAD-7. Arch Intern Med. 2006;166(10): 1092-7.

37. Sawaya H, Atoui M, Hamadeh A, Zeinoun P, Nahas Z. Adaptation and initial validation of the patient health questionnaire - 9 (PHQ-9) and the generalized anxiety disorder - 7 questionnaire (GAD-7) in an Arabic speaking Lebanese psychiatric outpatient sample. Psychiatry Res. 2016;239:245-52.

38. WANG Li LK, WANG Changying, SHENG Li, HU Dayi, DING Rongjing: Reliability and validity of GAD-2 and GAD-7 for anxiety screening in cardiovascular disease clinic. Sichuan Mental Health 2014, 27(3):198-201.

39. Hinz A, Klein AM, Brahler E, Glaesmer H, Luck T, Riedel-Heller SG, Wirkner K, Hilbert A. Psychometric evaluation of the generalized anxiety disorder screener GAD-7, based on a large German general population sample. J Affect Disord. 2017;210:338-44.

40. Suzuki T, Shiga T, Kuwahara K, Kobayashi S, Suzuki S, Nishimura K, Suzuki A, Omori H, Mori F, Ishigooka J, et al. Depression and outcomes in hospitalized Japanese patients with cardiovascular disease. - prospective single-center observational study. Circulation journal : official journal of the Japanese Circulation Society. 2011;75(10):2465-73.

41. Faller H, Steinbuchel T, Stork S, Schowalter M, Ertl G, Angermann CE. Impact of depression on quality of life assessment in heart failure. Int J Cardiol. 2010;142(2):133-7.

42. Brouwers C, Kupper N, Pelle AJ, Szabo BM, Westerhuis BL, Denollet J. Depressive symptoms in outpatients with heart failure: importance of inflammatory biomarkers, disease severity and personality. Psychology \& health. 2014;29(5):564-82.

43. Sokoreli I, de Vries JJ, Riistama JM, Pauws SC, Steyerberg EW, Tesanovic A, Geleijnse G, Goode KM, Crundall-Goode A, Kazmi S, et al. Depression as an independent prognostic factor for all-cause mortality after a hospital admission for worsening heart failure. Int J Cardiol. 2016;220:202-7.

44. Assari S, Zandi H, Ahmadi K, Kazemi Saleh D. Extent of coronary stenosis and anxiety symptoms among patients undergoing coronary angiography. The journal of Tehran Heart Center. 2017;12(4):155-9.

45. Vaccarino V, Sullivan S, Hammadah M, Wilmot K, Al Mheid I, Ramadan R, Elon L, Pimple PM, Garcia EV, Nye J, et al. Mental stress-induced-myocardial ischemia in Young patients with recent myocardial infarction: sex differences and mechanisms. Circulation. 2018;137(8):794-805.

46. Smolderen KG, Spertus JA, Gosch K, Dreyer RP, D'Onofrio G, Lichtman JH, Geda M, Beltrame J, Safdar B, Bueno H, et al. Depression treatment and health status outcomes in Young patients with acute myocardial infarction: insights from the VIRGO study (variation in recovery: role of gender on outcomes of Young AMI patients). Circulation. 2017;135(18):1762-4.

47. Kim JM, Stewart R, Lee YS, Lee HJ, Kim MC, Kim JW, Kang HJ, Bae KY, Kim SW, Shin IS, et al. Effect of escitalopram vs placebo treatment for depression on long-term cardiac outcomes in patients with acute coronary syndrome: a randomized clinical trial. Jama. 2018;320(4):350-8.

48. Yost G, Bhat G, Mahoney E, Tatooles A. Reduced anxiety and depression in patients with advanced heart failure after left ventricular assist device implantation. Psychosomatics. 2017:58(4):406-14.

49. O'Connor CM, Jiang W, Kuchibhatla M, Silva SG, Cuffe MS, Callwood DD, Zakhary B, Stough WG, Arias RM, Rivelli SK, et al. Safety and efficacy of sertraline for depression in patients with heart failure: results of the SADHART-CHF (sertraline against depression and heart disease in chronic heart failure) trial. J Am Coll Cardiol. 2010;56(9):692-9.

50. Angermann CE, Gelbrich G, Stork S, Gunold H, Edelmann F, Wachter R, Schunkert H, Graf T, Kindermann I, Haass M, et al. Effect of escitalopram on all-cause mortality and hospitalization in patients with heart failure and depression: the MOOD-HF randomized clinical trial. Jama. 2016;315(24): 2683-93. 